\title{
Inclusions in perovskite-magnetite-silicate rocks from Afrikanda, Russia: Clues to the early history of carbonatites?
}

\author{
N. J. Potter ${ }^{1}$, V. S. Kamenetsky ${ }^{1}$, A. R. Chakhmouradian ${ }^{2}$, K. Goemann ${ }^{3}$ \\ ${ }^{I}$ School of Physical Sciences, University of Tasmania, Australia, pottern@utas.edu.au, \\ dima.kamenetsky@utas.edu.au \\ ${ }^{2}$ Department of Geological Sciences, University of Manitoba, Canada, chakhmou@cc.umanitoba.ca \\ ${ }^{3}$ Central Science Laboratory, University of Tasmania, Australia, Karsten.Goemann@utas.edu.au
}

\section{Introduction}

The Devonian Kola Alkaline Province (KAP) hosts more than twenty alkaline-ultramafic rock complexes and is one of the largest carbonatite and alkaline magmatic provinces in the world. The Afrikanda massif is characterised by a large perovskite deposit and has been evaluated as a potential REE resource (Zaitsev et al., 2015). Afrikanda is composed of texturally and modally diverse olivinites and clinopyroxenites with a coarse-grained core grading through to fine-grained at the margin, crosscut by dikes of carbonatitic and foiditic rocks (Chakhmouradian and Zaitsev, 2004). Early crystallizing perovskite is typically an accessory phase in silica-undersaturated magmas and related rocks, yet is highly abundant throughout the Afrikanda complex. Our aim is to determine the processes involved in this unusual accumulation of perovskite.

\section{Perovskite textures}

Olivinites and clinopyroxenites from Afrikanda were examined by scanning electron microscopy (SEM) and electron backscattered diffraction (EBSD) to analyse textures, geochemistry and inclusions in perovskite. EBSD was used to identify the crystallographic orientation of perovskite grains and to examine the textural variation between samples. Perovskite $\left(\mathrm{CaTiO}_{3}\right)$ can constitute up to 60 vol. \% of a sample and contain variable REE, $\mathrm{Nb}, \mathrm{Sr}$ and Th contents (up to $9.5 \mathrm{wt} . \%$ total). The EBSD analysis enabled the identification of four textural types of perovskite (Fig 1-4). The olivinites exhibit type one (T1), while the clinopyroxenites display several types (T2-4).

T1 is characterised by euhedral perovskite crystals $(50-200 \mu \mathrm{m})$, occurring together to form a polygonal crystal mosaic with widespread $120^{\circ}$ triple-junctions (Fig. 1a). The crystals have no detectable zoning and a high abundance of multiphase inclusions. In the electron and Euler images (Fig. 1a, b) each perovskite crystal appears to be an individual grain, however in the $\mathrm{Z}$ direction (Fig. 1c) some of these grains are revealed as a composite of several subgrains with slight variations in orientation.

$\mathrm{T} 2$ is similar to $\mathrm{T} 1$ with an interlocked mosaic, prevalent $120^{\circ}$ triple-junctions and an abundance of multiphase inclusions (Fig. 2a). However, the perovskite grains $(50-270 \mu \mathrm{m})$ are subhedral to anhedral and the extent of zoning is variable across each sample; with some homogeneous areas and others with patchy zoning that crosses grain boundaries. Also some grains have rims of variable thickness displaying subtle oscillatory zoning. The presence of subgrains is also observed in T2 (Fig. 2b, c).

Perovskite in T3 are larger anhedral $(200 \mu \mathrm{m}-1 \mathrm{~mm})$ grains and form an intricate crystal mosaic with irregular grain boundaries (Fig. 3a). Zoning is discontinuous, patchy and may cross grain boundaries, and some grains show weakly developed zonation on grain margins. Multiphase inclusions are only abundant in some perovskite grains. Titanite occurs as irregular patches between minerals and as thin rims around most perovskite grains. Perovskite grain margins in contact with titanite are enriched in trace elements. Perovskite grain boundaries are difficult to identify using the electron image (Fig. 3a), but the grains are clearly visible in the EBSD image (Fig. 3b). EBSD reveals that T3 perovskite have significantly larger grainsize than T1 and T2, and that subgrains are still observed (Fig. 3b, c). 


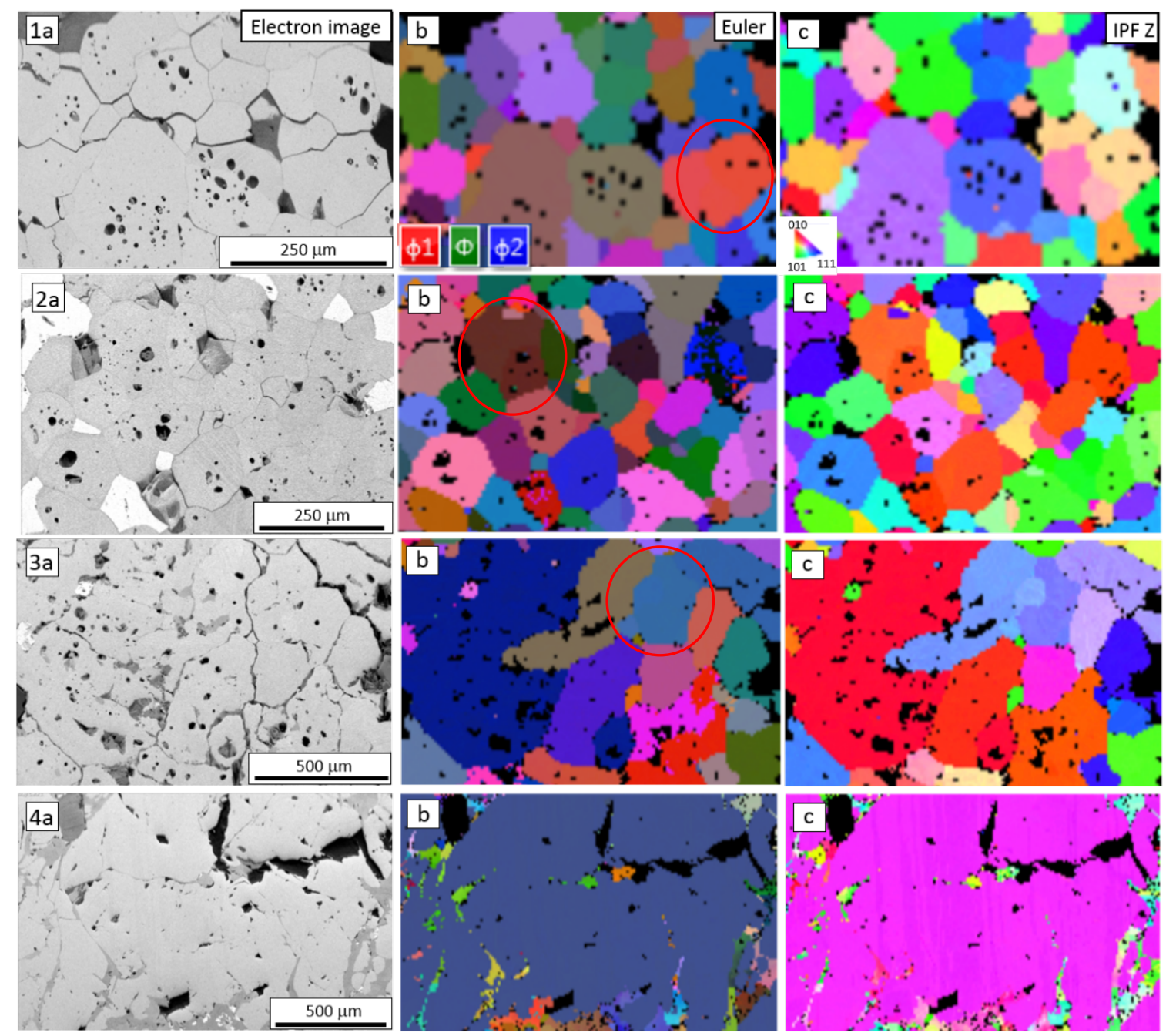

Figures 1-4: Display texture types T1 to T4, respectively. (a) Electron images of areas mapped, (b) Euler angle map using colours to denote the variety of crystal orientations in space using Euler angles: $\varphi 1$-red $\varphi$ green, $\varphi 2$-blue, (c) Inverse pole figure (IPZ) map in the $\mathrm{Z}$ direction showing varying crystal orientations in different colours. Red circles show grains that are composed of subgrains with different crystallographic orientations in the $\mathrm{Z}$ direction.

T4 perovskite is massive with highly irregular, patchy zoning, rare multiphase inclusions and interstitial titanite, calcite and loparite-(Ce) (Fig. 4a). These perovskite contain the highest concentrations of trace elements.

\section{Multiphase inclusions}

Multiphase inclusions are most abundant in $\mathrm{T} 1$ perovskite from olivinites and are not observed in other rock-forming minerals. The inclusions are variable in size and abundance, and preferentially occur in the cores of the perovskite grains. A total of 81 inclusions were analysed using SEM

\begin{tabular}{|c|c|c|c|}
\hline \multicolumn{2}{|l|}{ Silicates } & \multicolumn{2}{|l|}{ Carbonates } \\
\hline sodalite & 18 & nyerereite & 23 \\
\hline clinopyroxene & 15 & calcite & 15 \\
\hline melilite & 12 & shortite & 15 \\
\hline wollastonite & 12 & Na-Ca-Sr-carbonate & 4 \\
\hline forsterite & 10 & \multicolumn{2}{|l|}{ Oxides } \\
\hline diopside & 9 & magnetite & 27 \\
\hline humite & 8 & \multicolumn{2}{|l|}{ Phosphates } \\
\hline titanite & 4 & fluorapatite & 18 \\
\hline nepheline & 4 & apatite & 9 \\
\hline andradite & 4 & \multicolumn{2}{|l|}{ Sulphides } \\
\hline monticellite & 2 & pyrrhotite & 6 \\
\hline \multicolumn{2}{|c|}{ Water-bearing silicates } & chalcopyrite & 4 \\
\hline biotite & 42 & rasvumite & 4 \\
\hline pectolite & 29 & \multirow{5}{*}{\multicolumn{2}{|c|}{$\begin{array}{l}\text { Table 1: Tallied occurrence of } \\
\text { daughter phases in perovskite- } \\
\text { hosted inclusions from } \\
\text { olivinites. }\end{array}$}} \\
\hline cuspidine & 20 & & \\
\hline phlogopite & 16 & & \\
\hline chlorite & 5 & & \\
\hline magnesiohastingsite & 2 & & \\
\hline
\end{tabular}


and Raman spectroscopy. These inclusions exhibit rounded to negative crystallographic shapes and range from 5 to $30 \mu \mathrm{m}$, with an average of $10 \mu \mathrm{m}$. There is no relationship between perovskite grainsize and the abundance of inclusions. We identified more than 35 minerals in the inclusions (Table 1) with the phase assemblage differing significantly between and within perovskite grains and variable modal abundances of each component (Figs. 5a-c).
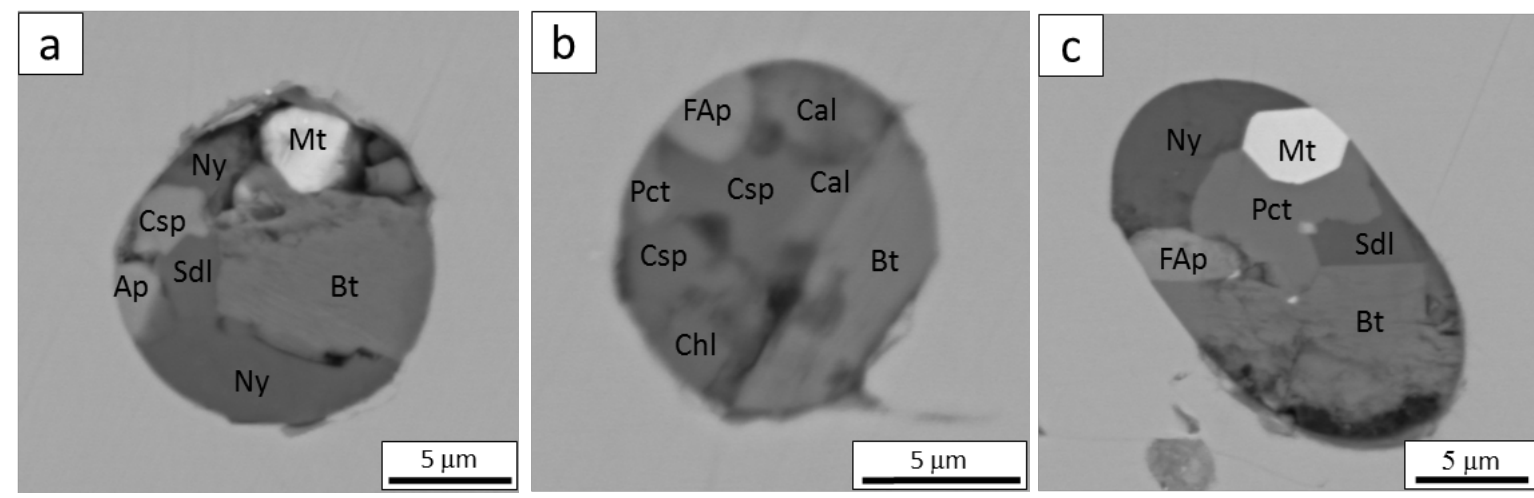

Figure 5: Back-scattered electron (BSE) SEM images of representative multiphase inclusions in perovskite, containing apatite $(\mathrm{Ap})$, biotite $(\mathrm{Bt})$, calcite $(\mathrm{Cal})$, clinochlore $(\mathrm{Chl})$, cuspidine (Csp), fluorapatite (FAp), magnetite $(\mathrm{Mt})$, nyerereite $(\mathrm{Ny})$, pectolite $(\mathrm{Pct})$, sodalite $(\mathrm{Sdl})$.

\section{Discussion}

The textures show the systematic transformation of perovskite from a mosaic of individual perovskite grains to massive perovskite with interstitial titanite and an associated high concentration of trace elements. The observed progression of perovskite textures and compositions in the samples are key to interpreting the multistage evolution of the accumulating perovskite and the development of massive textures.

The range of minerals in the inclusions and the contrast in mineral assemblage of adjacent inclusions is unusual. These inclusions are likely to be primary and were trapped during perovskite growth. Evidence is based on their rounded shape, distribution of inclusions within the interior of grains and lack of alignment with fractures. The absence of glass suggests that the mineral constituents of inclusions were mostly trapped in solid state. The variety of inclusion compositions within the same grain could be a result of a heterogeneous multiphase environment. If they are primary inclusions the coexistence of silicate- and carbonate-dominated assemblages in the inclusions of oxide-dominated rocks are unlikely to represent the parental medium but could provide insight into the composition of the environment that crystallised perovskite.

\section{References}

Chakhmouradian AR, Zaitsev AN (2004) Afrikanda: an association of ultramafic, alkaline and alkalisilica rich carbonatitic rocks from mantle-derived melts. In: Wall F, Zaitsev AN (ed) Phoscorites and Carbonatites from Mantle to Mine: The Key Example of the Kola Alkaline Province, Mineralogical Society, London, pp 247-291

Zaitsev AN, Williams CT, Jeffries TE, Strekopytov S, Moutte J, Ivashchenkova OV, Spratt J, Petrov SV, Wall F, Seltmann R, Borozdin AP (2015) Rare earth elements in phoscorites and carbonatites of the Devonian Kola Alkaline Province, Russia: Examples from Kovdor, Khibina, Vuoriyarvi and Turiy Mys complexes. Ore Geology Reviews 64:477-498 